Final Version available online at: $\quad$ http://dx.doi.org/10.1016/j.biortech.2014.10.117

\title{
Utilization of biodiesel-derived glycerol or xylose for increased growth and lipid production by indigenous microalgae
}

\author{
Gustavo B. Leite, Kiran Paranjape, Ahmed E.M. Abdelaziz and Patrick C. Hallenbeck* \\ Département de microbiologie, infectiologie, et immunologie, Université de Montréal, \\ CP 6128, Centre-ville, Montréal. PQ H3C 3J7 Canada
}

*Corresponding author: patrick.hallenbeck@umontreal.ca, fax: 514-343-5701

\begin{abstract}
The use of industrial wastes rich in mineral nutrients and carbon sources to increase the final microalgal biomass and lipid yield at a low cost is an important strategy to make algal biofuel technology viable. Using strains from the microalgal collection of the Université de Montréal, this report shows for the first time that microalgal strains can be grown on xylose, the major carbon source found in wastewater streams from pulp and paper industries, with an increase in growth rate of 2.8 fold in comparison to photoautotrophic growth, reaching up to $\mu=1.1$ day. On glycerol, growth rates reached as high as $\mu=1.52$ /day. Lipid productivity increased up to $370 \%$ on glycerol and $180 \%$ on xylose for the strain LB1H10, showing the suitability of this strain for further development for biofuels production through mixotrophic cultivation.
\end{abstract}

Leite, G. B.; Paranjabe, K.; Abdelaziz, A. E. M; Hallenbeck, P. C. (2014) Utilization of biodieselderived glycerol or xylose for increased growth and lipid production by indigenous microalgae. Bioresource Technology, in press. Available online 30 October 2014 
Final Version available online at: http://dx.doi.org/10.1016/j.biortech.2014.10.117

\section{Introduction}

After the industrial revolution, the development of the new social system required a mobile, cheap and easy to use energy source. Petroleum was the most obvious choice, fueling the exponential growth of the world population from one billion in the eighteen hundreds to more than seven billion people in 2014. However, the versatility of crude oil has proved to be a double-edged sword, creating a society dependent upon oil as the main source of energy and the most important feedstock for the chemical industry. Today, the full consequences of an abrupt interruption in crude oil supplies are unimaginable, but the era of cheap and abundant oil is already gone. The ever growing demand, with ramped-up prices over the last few decades, and the perspective of a decline in oil production rates (peak oil) in the near future, indicate that we are reaching a critical point (Nashawi et al. 2010). Moreover, the direct and indirect toll on the environment and health systems is beginning to change the cost-benefit calculus of using this black gold. The transportation sector alone consumes more than $70 \%$ of the crude oil produced, making the development of biofuels an essential element in any strategy to decrease fossil fuel dependency (Abdelaziz et al. 2013).

Deriving biofuels from microalgae is an interesting proposition since they can be grown using sustainable cultivation systems, which do not require arable land and therefore don't displace food crops. In general, microalgae have faster growth rates and higher lipid yields than traditional oil crops, producing drop-in fuels which do not require modification of the present storage and distribution systems, and little to no modification of current internal combustion engines. Many algal species produce considerable amounts of triacylglycerol (TAG), easily converted into biodiesel, as an energy reserve (Cerón-García et al. 2013). However, like more traditional agriculture, microalgal productivity is of course limited by photosynthetic efficiency, a fact very relevant to geographical locations with a low annual solar irradiation.

Many algal species are capable of assimilating different carbon sources while harvesting light energy (Ukeles \& Rose 1976). Mixotrophic cultivation could represent an important strategy for microalgal production in many situations, including locations in 
Final Version available online at: http://dx.doi.org/10.1016/j.biortech.2014.10.117

high latitudes. However, the addition of organic carbon to the culture medium could significantly impact the operational cost, constituting between $35 \%$ and $80 \%$ of the medium price depending on the choice of carbon source (Cheng et al. 2009; X. Li et al. 2007). In addition, supplementation with organic fixed carbon can have a negative impact on the sustainability footprint if its production competes with that of food crops. Thus, carbon sources to be used in algal medium should preferably be industrial wastes. Among the possible options, the most obvious one is probably glycerol, an important biofuel waste since it represents about $10 \%$ of the products of TAG transesterification. With the vast amount of biodiesel presently made from oil crops, more than a billion kilograms of crude glycerol are produced annually, with a corresponding drastic decline in its value. The availability of crude (or technical) glycerol as a cheap carbon source has led to many studies evaluating the use of crude glycerol as feedstock for the biological production of valuable chemicals as dihydroxyacetone, citric acid, vancomicin, cephalosporine and others (Dobson et al. 2012; Liu et al. 2013; Morgunov et al. 2013; Shin et al. 2011; Zeng et al. 2013). However, if these conversion processes are successful, the value of their products, produced at enormous levels, would also fall precipitously. The only product for which there is a nearly insatiable market is some type of fuel. Indeed, the heterotrophic production of ethanol, butanol and hydrogen using fungi or bacteria has also been reported (Dobson et al. 2012; Ghosh et al. 2012; SabourinProvost \& Hallenbeck 2009). Heterotrophic cultivation of the alga Chlorella protothecoides showed equivalent growth on pure or crude glycerol (Y.-H. Chen \& Walker 2011). Recently, mixotrophic cultivation of Chlorella vulgaris on glycerol and glucose was shown to give higher yields (Kong et al. 2013), while another study with Chlorella pyrenoidosa showed a 20 fold increase in lipid productivity under mixotrophic conditions (Rai et al. 2013).

Another abundant waste that is available worldwide comes from the pulp and paper industry. The waste stream from pulp production is rich in xylose, turning it into a putative cheap source of carbon with high chemical energy content (Pérez et al. 2002). One suggested strategy is the chemical transformation of this waste into valuable products such as furfural and carboxylic acids (Xing et al. 2011), or directly into fuels

Leite, G. B.; Paranjabe, K.; Abdelaziz, A. E. M; Hallenbeck, P. C. (2014) Utilization of biodieselderived glycerol or xylose for increased growth and lipid production by indigenous microalgae. Bioresource Technology, in press. Available online 30 October 2014 
Final Version available online at: http://dx.doi.org/10.1016/j.biortech.2014.10.117

(Xing et al. 2010). However, these processes are highly dependent on the purity of the waste stream and face several challenges before being scaled up. Biological approaches being developed include production of PHB (polyhydroxybutyrate), a feedstock for the production of bioplastics (Garcez Lopes et al. 2011); and biofuels, such as ethanol, isobutanol and triacylglycerol (TAG) (Brat \& Boles 2013; Kurosawa et al. 2013; Q. Li et al. 2008). Nevertheless, all current proposed biological approaches use either prokaryotes or fungi only and until now the utilization of xylose by algae has not been reported.

The use of these types of substrates can therefore not only provide cheap fixed carbon for potentially augmenting algal growth and lipid production, but can also serve a valuable function in waste treatment. Here, the photoautotrophic, heterotrophic and mixotrophic growth and lipid productivity performance of ten strains indigenous to Quebec (Abdelaziz et al. 2014) was assessed using glycerol or xylose as alternative carbon sources.

\section{Methods}

\subsection{Strains and cultivation}

The strains used in this work are part of the collection of the Département de microbiologie, infectiologie et immunology of the Université de Montréal. These are indigenous strains of mainly Chlorella sp. isolated in the region of Québec, Canada, and were previously described (Abdelaziz et al. 2014). The medium used for photoautotrophic cultivation was the Bold's Basal Medium (BBM) described by Andersen (Andersen 2005). For the mixotrophic cultivation, BBM was supplemented with $20 \mathrm{mM}$ xylose or glycerol.

The pre-inoculum was grown using photoautotrophic conditions (BBM medium only) in 12-well plates until mid-log phase. The cultures were diluted to an optical density at $630 \mathrm{~nm}\left(\mathrm{OD}_{630}\right)$ of 0.1 and used for inoculum $(5 \% \mathrm{v} / \mathrm{v})$. Three biological replicates of each algal strain were grown for 17 days in 12 well microtiter plates containing $3.5 \mathrm{~mL}$ of culture medium, and illuminated under a light/dark cycle of 12

Leite, G. B.; Paranjabe, K.; Abdelaziz, A. E. M; Hallenbeck, P. C. (2014) Utilization of biodieselderived glycerol or xylose for increased growth and lipid production by indigenous microalgae. Bioresource Technology, in press. Available online 30 October 2014 
Final Version available online at: http://dx.doi.org/10.1016/j.biortech.2014.10.117

hours using day-light LED boards at an incident light intensity of $40 \mathrm{~W} / \mathrm{m}^{2}$ (approximately $190 \mu \mathrm{E} / \mathrm{m}^{2} / \mathrm{s}$ ) Each strain and medium condition was also carried out in continuous darkness (biological triplicates) to provide a comparison under heterotrophic conditions. Growth was measured by reading the optical density at $630 \mathrm{~nm}$ using a microtiter plate reader (Biotek EL800). Growth rates were calculated according to equation 1 (eq.1) using the optical density data $\left(\mathrm{OD}_{630}\right)$ between days 1 and 4 of cultivation.

Eq.1 $\quad \mu \mathrm{d}^{-1}=\left(\operatorname{lnOD}_{630}{ }^{\mathrm{f}}-\operatorname{lnOD}_{630}{ }^{\mathrm{i}}\right) / \mathrm{t}^{\mathrm{f}}-\mathrm{t}^{\mathrm{i}}$

Eq.1. Growth rate formula used, where $\mu \mathrm{d}^{-1}=$ growth rate per day; $\operatorname{lnOD}_{630}{ }^{\mathrm{f}}=$ final optical density; $\operatorname{lnOD}_{630}{ }^{\mathrm{i}}=$ initial optical density; $\mathrm{t}^{\mathrm{f}}=$ final time in days, $\mathrm{t}^{\mathrm{i}}=$ initial time in days

\subsection{Spectrophotometric determination of nitrate, glycerol and xylose}

The amounts of residual nitrate, glycerol or xylose were assessed in analytical triplicates. Established colorimetric methods were adapted for use in 96 well plate format and were performed for each of the biological replicates. The results are shown as the mean of the nine values obtained for each strain. At the end of the growth period the samples were centrifuged at $2000 \mathrm{~g}$ for 8 minutes and the supernatant used for analysis. The classic colorimetric assay for quantification of reducing sugars using 3,5dinitrosalicylic acid was adapted for measurement of xylose (Miller 1959). $90 \mu \mathrm{L}$ of DNS solution $(10 \mathrm{~g} / \mathrm{L}$ dinitrosalicylic acid; $10 \mathrm{~g} / \mathrm{L}$ sodium hydroxide; $0.5 \mathrm{~g} / \mathrm{L}$ sodium sulphite) was mixed with $90 \mu \mathrm{L}$ of the sample or standard and incubated for 15 minutes in a water bath at $90^{\circ} \mathrm{C}$; immediately cooled down in an ice bath, and then $30 \mu \mathrm{L}$ of $40 \%$ potassium sodium tartrate solution was added to stop the reaction. The optical density at $630 \mathrm{~nm}$ (Biotek EL800 microtiter plate reader) was compared to a standard curve obtained under the same conditions.

Glycerol was quantified using the colorimetric method described by Bondioli and Bella (Bondioli \& Bella 2005), a two process with the periodate oxidation of glycerol followed by the formation of formaldehyde through Hantzsch's reaction. Here, $100 \mu \mathrm{L}$ of

Leite, G. B.; Paranjabe, K.; Abdelaziz, A. E. M; Hallenbeck, P. C. (2014) Utilization of biodieselderived glycerol or xylose for increased growth and lipid production by indigenous microalgae. Bioresource Technology, in press. Available online 30 October 2014 
Final Version available online at: http://dx.doi.org/10.1016/j.biortech.2014.10.117

samples or standards were placed in a 96 well plate, mixed with $60 \mu \mathrm{L}$ of the sodium periodate solution followed by $60 \mu \mathrm{L}$ of acetylacetone solution, mixed and incubated in a water bath at $70^{\circ} \mathrm{C}$ for one minute, cooled down immediately in a water bath to room temperature and the optical density at 530nm was then read in a Biotek EL800 microplate reader. Both these solutions were prepared daily as previously described (Bondioli \& Bella 2005).

The residual nitrate in the culture broth after 17 days of cultivation was detected using the method described by Bartzatt et. al (Bartzatt \& Donigan 2004). Here, 20 $\mu \mathrm{L}$ of sample was placed in a 96 well plate and mixed with $90 \mu \mathrm{L}$ of diphenylamine solution (3.34g of diphenylamine in $14.4 \mathrm{M} \mathrm{H}_{2} \mathrm{SO}_{4}$ ) and $85 \mu \mathrm{L}$ of pure $\mathrm{H}_{2} \mathrm{SO}_{4}$ was then added. The microplates were shaken for 10 minutes and the read $\left(\mathrm{OD}_{630}\right)$ using the Biotek EL800 microplate reader .

\subsection{Assessment of bacterial contamination}

Since the strains used were not necessarily axenic, it was important to determine the degree. At the end of the cultivation period, an aliquot of each culture was diluted to reach a concentration of $500+/$ - algal cells per $\mathrm{mL}$ and $100 \mu \mathrm{L}$ was plated on LB agar. Colonies were counted after $48 \mathrm{~h}$ incubation at $37^{\circ} \mathrm{C}$. An estimate of the potential contribution of bacterial biomass to the optical density readings was made using a culture of Escherichia coli DH5a together with plating and optical density readings as noted above. This analysis shows that on the average, bacterial contamination probably contributed no more that $2.2 \%$ of the final biomass, and in the worst case no more than $14 \%$.

\subsection{Lipid Quantification}

The algal lipid content was quantified using Nile Red fluorescence measurements. Nile Red is considered an efficient dye for algal neutral lipids (Bertozzini et al. 2011; W. Chen et al. 2009; Elsey et al. 2007; Huang et al. 2009; Kou et al. 2013; Lee 1998). In this 
work we adapted the method previously described by (Abdelaziz et al. 2014). After 17 days of incubation, $50 \mu \mathrm{L}$ of the algal culture sample was stained with Nile Red at $0.5 \mu \mathrm{g} / \mathrm{mL}$ final concentration, using dimethylsulfoxide (DMSO) at $25 \%$ as carrier. The assay was brought to a final volume of $200 \mu \mathrm{L}$ and was incubated for 15 minutes with agitation using a microtiter plate shaker (DSG Titertek Flow Laboratories, Meckenheim, Germany). The fluorescence was then read in a Synergy NEO HTS Microplate Reader with excitation set to $520 \mathrm{~nm}$ and emission captured at $570 \mathrm{~nm}$. The fluorescence output was then compared to a standard curve made using extra virgin olive oil. The values are indicated as the average of three analytical readings of each biological replicate.

For the lipid profile analysis, triacylglycerols (TAGs) were extracted and transesterified in a single step, following methods already described (Cao et al. 2013). Approximately $33 \mathrm{mg}$ of dried biomass was placed in $2 \mathrm{~mL}$ screw cap microcentrifuge tube, $500 \mu \mathrm{L}$ of a methanol solution acidified with $10 \%$ sulphuric acid were added, it was heated to $90^{\circ} \mathrm{C}$ for 90 minutes (mixed in a vortex mixer every ten minutes) and allowed to cool to room temperature. Then, $1 \mathrm{~mL}$ of $\mathrm{n}$-Hexane was added and vortexed for 1 minute. Cell debris was pelleted by centrifugation and the supernatant saved in a glass test tube. The hexane step was then repeated 4 more times, adding the supernatant to the same glass tube, which was then heated to $90^{\circ} \mathrm{C}$ for 20 minutes, allowed to cool down to room temperature and the proper phase was collected and stored at $-20^{\circ} \mathrm{C}$. The lipid profile was analyzed in an Agilent 7890A gas chromatograph (GC) equipped with the column Omegawax 250. An internal control (50 $\mu \mathrm{L}$ of C19:0) was added to each $250 \mu \mathrm{L}$ of FAME.

\subsection{Statistical analysis}

A parametric, paired, two-tailed t-test was performed using Prism 6.0D software (GraphPad) to determine if differences in biomass productivity or growth curves were influenced by exposition to light.

Leite, G. B.; Paranjabe, K.; Abdelaziz, A. E. M; Hallenbeck, P. C. (2014) Utilization of biodieselderived glycerol or xylose for increased growth and lipid production by indigenous microalgae. Bioresource Technology, in press. Available online 30 October 2014 
Final Version available online at: http://dx.doi.org/10.1016/j.biortech.2014.10.117

\section{Results and Discussion}

Ten microalgal strains indigenous to Quebec were examined for biomass and lipid productivity under different growth modes: photoautotrophic, mixotrophic (light), and heterotrophic (dark) using $\mathrm{CO}_{2}$ and/or glycerol or xylose. Glycerol and xylose in particular were considered since a large quantity of "waste" glycerol is currently available as a side-product of biodiesel manufacture $(1 \mathrm{~kg}$ glycerol per ten $\mathrm{kg}$ of biodiesel produced), and xylose is abundant in hemicellulose waste-streams of the pulp and paper industry. The strains were tentatively identified as Chlorella $s p$. based on morphological characteristics as determined by light microscopy.

\subsection{Maximal growth rates under the different conditions}

One important aspect is the influence of glycerol and xylose on growth rates and yields under the different conditions. These were calculated by choosing a period of time that would include the active growth period of all the strains under the different kinds of treatments, yet being restricted to the growth phase as much as possible. It is important to note that, while this method provides an important tool for comparing the performance of these strains under different conditions, it is also likely to underestimate the performance of some strains. Thus, the reported growth rates are conservative.

The different strains were quite varied in their responses. The variation in patterns of growth can be seen in Figure 1 for selected strains. However a number of generalizations can be made (Table 1). First, it is notable that all the strains examined were capable of some degree of heterotrophic (in the dark) growth on the two different organic carbon substrates. As far as we are aware, this is the first report of the utilization of xylose by microalgae. The majority of the strains $(7 / 10)$ showed an enhancement in growth rate, up to 2.8-fold (PCH44), whereas three were relatively unaffected by its presence. In contrast, in all but two strains, LB1H10 and PCH44, the presence of xylose decreased the growth rate in the light. In the dark, not surprisingly, the controls $\left(\mathrm{CO}_{2}\right.$ only) did not show any growth (not shown). However, half the strains (LB1H09, 
Final Version available online at: http://dx.doi.org/10.1016/j.biortech.2014.10.117

LB1H10, MA2H01, PCH03, and PCH44) had a growth rate that was higher, up to 2.6fold (PCH44) than when incubated under photoautotrophic conditions. The others showed a decreased growth rate under these conditions, with PCH90 having only $40 \%$ of its photoautotrophic growth rate. In stark contrast to glycerol, xylose in general decreased the growth rate when added to cultures incubated in the light. The only exceptions were LB1H10 and $\mathrm{PCH} 44$ whose growth rate was moderately stimulated in the presence of xylose. This trend was also seen in dark xylose incubated cultures where the majority (7/10) were also inhibited by xylose, when compared to their growth rate under photoautotrophic conditions. Averaging the results of all the strains together gives a growth rate under photoautotrophic conditions of $0.98 \mu / \mathrm{d}$, less than with glycerol in the light, $1.52 \mu / \mathrm{d}$, or in the dark, $1.42 \mu / \mathrm{d}$. Average growth on xylose was not as good, $1.096 \mu / \mathrm{d}$ (light) and $0.881 \mu / \mathrm{d}$ (dark).

\subsection{The influence of glycerol on final biomass and lipid yields}

As discussed above, all the strains showed the capacity for heterotrophic growth (in the dark) using glycerol as sole carbon source and the cultures seemed to be capable of metabolizing this compound in the light as under both conditions assays showed that the glycerol in the medium had been completely consumed by the end of the cultivation period. As well, there was no detectable nitrate left in any of the cultures at this point in cultivation. In general, as was noted above for the growth rates, growth with glycerol in the light gave higher biomass yields than growth in the dark (Figure 2). However, strikingly, final biomass yields in the light were, with only one exception (LB1H10), lower in the presence of glycerol than in its absence in spite of what were generally higher maximal growth rates. An examination of the growth curves (some examples are shown in Figure 1) shows that this is the case because the two different types of culture show different growth patterns. Cultures with glycerol added show little to no lag phase and quickly reach maximal growth rates as opposed to photoautotrophic cultures which have an appreciable lag phase, reach a lower maximal growth rate, but are able to maintain this over a longer period of time, thus reaching a higher final cell density. Eight

Leite, G. B.; Paranjabe, K.; Abdelaziz, A. E. M; Hallenbeck, P. C. (2014) Utilization of biodieselderived glycerol or xylose for increased growth and lipid production by indigenous microalgae. Bioresource Technology, in press. Available online 30 October 2014 
of the ten strains had higher final biomass production when grown with glycerol in the light cycle compared to the dark, with the other two (LB1H09 and PCH44) showing no significant difference between the two conditions (Figure 2).

While the addition of glycerol did not lead to an increase in the production of biomass above that found under photoautotrophic conditions, with the exception of strain LB1H10, lipid production was higher for eight of the ten strains when cultivated under these conditions (Figure 3). Once again, the highest increase was for strain LB1H10, which showed a $370 \%$ increase in lipids compared to photoautotrophic conditions. The increase in lipids represented only $10 \%$ of the total extra produced biomass, what can probably be further optimized. Strain LB1H12 tripled its lipid productivity, and three other strains doubled it (Figure 3, Table S1). That lipid productivity increased in spite of the overall decreased biomass yields was a reflection of the very large increase in some cases in the cellular lipid content (Figure 4). The lipid content of most cultures increased more than two-fold, with two, LB1H09 and PCH03 showing a nearly five-fold increase and LB1H12 giving a remarkable more than seven-fold increase in lipid content. In spite of the large increase in the productivity of most strains, the best natural lipid producer under photoautotrophic conditions, $\mathrm{PCH} 90$, in fact suffered a slight decrease in productivity in medium with glycerol. This strain showed a similar pattern of growth under photoautotrophic and mixotrophic conditions, and further optimization would be necessary to increase yields with added organic carbon. Nevertheless, lipid productivities shown here during mixotrophic cultivation with glycerol are several fold higher than previously reported (Y.-H. Chen and Walker, 2011; Kong et al., 2013; Rai et al., 2013).

In contrast to the augmentation in lipid production in the light when glycerol is added to the medium, even though the strains can all grow in the dark at the expense of glycerol, lipid production was low (Figure 3), a reflection of both the lower biomass yields under these conditions and the relatively low cellular lipid content (Figure 4). The remarkable increase in lipid content with some strains in the presence of glycerol in the light suggests that further research, in particular to increase biomass yields under these conditions, could lead to very significant increases in overall lipid productivity. 
Final Version available online at: http://dx.doi.org/10.1016/j.biortech.2014.10.117

\subsection{The influence of xylose on final biomass and lipid yields}

Xylose is a major carbon source found in wastewater discharged by the paper/pulp industry. Little work has previously been done on the utilization of xylose by microalgae, and if strains capable of utilizing xylose were found and suitable bioprocess strategies developed, it might be possible to simultaneously treat these wastes and produce fuel or fuel precursors. Therefore, the performance of the same isolates when grown in the presence of xylose was assessed. Only one strain, LB1H10, showed a significant enhancement in growth rate when incubated in the light in the presence of xylose (Table 1). Strain PCH44 grew only slightly faster in with xylose, and the growth of all the other strains was significantly decreased by the presence of this substrate. Interestingly, all the strains were capable of some heterotrophic growth on xylose, and growth rates under these conditions were similar to those observed under photoautotrophic conditions.

In terms of growth yields, xylose appears to be a poor candidate for alternative carbon source. The biomass yield was low, and three out of ten strains (LB1H09; PCH03; PCH44) had negligible growth under either condition: light or dark (Figure 2, Table S1). All strains showed a lower biomass production on xylose than in the other conditions examined; photoautotrophic, and cultures with added glycerol, light and dark. In fact, growth is so drastically reduced that it suggests a direct or indirect growth inhibition by this substrate. Interestingly, the biomass productivity was consistently higher in dark than in the light ( $\mathrm{P}=0.018$ ), with the sole exception of LB1H10 (Figure 2, Table S1), implying that light has a negative influence when xylose is present.

With the exception of LB1H10, lipid productivity in the presence of xylose was poor, in general much less than that seen under photoautotrophic conditions (Figure 3). Although the cellular lipid content in some strains significantly increased when incubated with xylose in the light (strains PCH05, PCH06, PCH44, and PCH90) (Figure 4), this was more than offset by the drastic decrease in biomass under these conditions (Figure 2). As with glycerol, little or no enhancement in lipid content was seen when the cultures were incubated with xylose in the dark, with the sole exception of LB1H10 (discussed in detail below).

Leite, G. B.; Paranjabe, K.; Abdelaziz, A. E. M; Hallenbeck, P. C. (2014) Utilization of biodieselderived glycerol or xylose for increased growth and lipid production by indigenous microalgae. Bioresource Technology, in press. Available online 30 October 2014 


\subsection{Unique characteristics of $\mathrm{LB} 1 \mathrm{H} 10$ as a promising biofuels producer}

Thus, with both carbon sources, the performance of strain LB1H10 stands apart from the other strains tested. This strain appears to possess the ability of actively assimilate glycerol in the light, producing both higher levels of biomass and increasing its lipid productivity. Moreover, under mixotrophic conditions, this strain produces nearly four-fold higher amounts of lipid (Figure 3). In addition, LB1H10 shows significant in terms of the conversion of xylose to biomass and lipid. This strain accumulated significant amounts of biomass from xylose both in the light (76\% of photoautotrophic) and in the dark (54\% of photoautotrophic). Since lipid content is augmented with xylose both in the light and the dark (Figure 4), this means that this culture shows important increases in lipid productivity with xylose, from more than three-fold in the light to almost two-fold in the dark. The neutral lipid profile was examined after conversion to FAMES (fatty acid methyl esters) (Figure 5). This analysis showed that the molecules of interest for biodiesel production C14, C16, C18 saturated or mono-saturated FAs, account for at least $58 \%$ of the total lipids under photoautotrophic conditions with even higher percentages when grown in the presence of fixed carbon; $67 \%$ with xylose and $63 \%$ with glycerol (Figure 5A). There was little variation of the FAME profile with growth conditions. Interestingly, the quantites of PUFAs (poly-unsaturated fatty acids) were also relativel high: $5 \%$ photoautotrophic, $4.2 \%$ with xylose, and $7.3 \%$ with glycerol (Figure 5B). Thus, development of a bioprocess involving this strain might hold promise for dual pulp and paper mill wastewater treatment and biofuels production.

\subsection{Conclusions}

In the initial screening of ten strains reported here, a number were shown to possess interesting characteristics in terms of fixed carbon utilization. Yields of lipids and biomass are likely to be improved in future optimization studies. Nevertheless some of the strains showed lipid productivity during mixotrophic cultivation with glycerol that

Leite, G. B.; Paranjabe, K.; Abdelaziz, A. E. M; Hallenbeck, P. C. (2014) Utilization of biodieselderived glycerol or xylose for increased growth and lipid production by indigenous microalgae. Bioresource Technology, in press. Available online 30 October 2014 
Final Version available online at: http://dx.doi.org/10.1016/j.biortech.2014.10.117

was several fold higher than previously reported. One strain showed efficient use of both carbon sources in the light, gaining increased biomass: 39\% more with xylose and $96 \%$ more with glycerol. To our knowledge, this is the first report of xylose utilization by a microalga.

\section{Acknowledgements}

This research was supported by a Grant from FQRNT (Le Fonds Québécois de la recherche sur la nature et les technologies), programme de recherche en partenariat contribuant à la séquestration des gaz à effet de serre (2011-GZ-141307) to P.C.H. We thank Patrick McGinn and Shabana Bhatti (Halifax, NS), NRC Institute for Marine Biosciences, for advice and training at the Ketch Harbour Research Center and for the FAME analysis.

Leite, G. B.; Paranjabe, K.; Abdelaziz, A. E. M; Hallenbeck, P. C. (2014) Utilization of biodieselderived glycerol or xylose for increased growth and lipid production by indigenous microalgae. Bioresource Technology, in press. Available online 30 October 2014 
Final Version available online at: $\quad$ http://dx.doi.org/10.1016/j.biortech.2014.10.117

\section{References}

Abdelaziz, A.E.M. et al., 2014. Screening microalgae native to Quebec for wastewater treatment and biodiesel production. Bioresource Technology, 157, pp.140-148.

Abdelaziz, A.E.M., Leite, G.B. \& Hallenbeck, P.C., 2013. Addressing the challenges for sustainable production of algal biofuels: I. Algal strains and nutrient supply. Environmental Technology, 34(13-14), pp.1783-1805.

Andersen, R.A., 2005. Algal Culturing Techniques, San Diego: Elsevier/Academic Press.

Bartzatt, R. \& Donigan, L., 2004. The colorimetric determination of nitrate anion in aqueous and solid samples utilizing an aromatic derivative in acidic solvent. Toxicological \& Environmental Chemistry, 86(2), pp.75-85.

Bertozzini, E. et al., 2011. Application of the standard addition method for the absolute quantification of neutral lipids in microalgae using Nile red. Journal of Microbiological Methods, 87(1), pp.17-23.

Bondioli, P. \& Bella, Della, L., 2005. An alternative spectrophotometric method for the determination of free glycerol in biodiesel. EUROPEAN JOURNAL OF LIPID SCIENCE AND TECHNOLOGY, 107(3), pp.153-157.

Brat, D. \& Boles, E., 2013. Isobutanol production from D-xylose by recombinant Saccharomyces cerevisiae. Fems Yeast Research, 13(2), pp.241-244.

Cao, H. et al., 2013. Direct Biodiesel Production from Wet Microalgae Biomass of Chlorella pyrenoidosa through In Situ Transesterification. BioMed Research International, 2013, pp.1-6.

Leite, G. B.; Paranjabe, K.; Abdelaziz, A. E. M; Hallenbeck, P. C. (2014) Utilization of biodieselderived glycerol or xylose for increased growth and lipid production by indigenous microalgae. Bioresource Technology, in press. Available online 30 October 2014 
Final Version available online at: http://dx.doi.org/10.1016/j.biortech.2014.10.117

Cerón-García, M.C. et al., 2013. Mixotrophic growth of Phaeodactylum tricornutum on fructose and glycerol in fed-batch and semi-continuous modes. Bioresource Technology, 147, pp.569-576.

Chen, W. et al., 2009. A high throughput Nile red method for quantitative measurement of neutral lipids in microalgae. Journal of Microbiological Methods, 77(1), pp.41-47.

Chen, Y.-H. \& Walker, T.H., 2011. Biomass and lipid production of heterotrophic microalgae Chlorella protothecoides by using biodiesel-derived crude glycerol. Biotechnology Letters, 33(10), pp.1973-1983.

Cheng, Y. et al., 2009. Alga-Based Biodiesel Production and Optimization Using Sugar Cane as the Feedstock. Energy \& Fuels, 23(8), pp.4166-4173.

Dobson, R., Gray, V. \& Rumbold, K., 2012. Microbial utilization of crude glycerol for the production of value-added products. Journal of Industrial Microbiology \& Biotechnology, 39(2), pp.217-226.

Elsey, D. et al., 2007. Fluorescent measurement of microalgal neutral lipids. Journal of Microbiological Methods, 68(3), pp.639-642.

Garcez Lopes, M.S. et al., 2011. PHB Biosynthesis in Catabolite Repression Mutant of Burkholderia sacchari. Current microbiology, 63(4), pp.319-326.

Ghosh, D., Sobro, I.F. \& Hallenbeck, P.C., 2012. Stoichiometric conversion of biodiesel derived crude glycerol to hydrogen: Response surface methodology study of the effects of light intensity and crude glycerol and glutamate concentration. Bioresource Technology, 106, pp.154-160. 
Final Version available online at: http://dx.doi.org/10.1016/j.biortech.2014.10.117

Huang, G.-H., Chen, G. \& Chen, F., 2009. Rapid screening method for lipid production in alga based on Nile red fluorescence. Biomass and Bioenergy, 33(10), pp.13861392.

Kong, W.-B. et al., 2013. Effect of Glycerol and Glucose on the Enhancement of Biomass, Lipid and Soluble Carbohydrate Production by Chlorella vulgaris in Mixotrophic Culture. Food Technology and Biotechnology, 51(1), pp.62-69.

Kou, Z. et al., 2013. Fluorescent measurement of lipid content in the model organism Chlamydomonas reinhardtii. Journal of Applied Phycology, 25(6), pp.1633-1641.

Kurosawa, K., Wewetzer, S.J. \& Sinskey, A.J., 2013. Engineering xylose metabolism in triacylglycerol-producing Rhodococcus opacus for lignocellulosic fuel production. Biotechnology for Biofuels, 6 .

Lee, S.Y., 1998. Poly(3-hydroxybutyrate) production from xylose by recombinant Escherichia coli. Bioprocess Engineering, 18(5), pp.397-399.

Li, Q., Du, W. \& Liu, D., 2008. Perspectives of microbial oils for biodiesel production. Applied Microbiology and Biotechnology, 80(5), pp.749-756.

Li, X., Xu, H. \& Wu, Q., 2007. Large-scale biodiesel production from microalga Chlorella protothecoides through heterotrophic cultivation in bioreactors. Biotechnology and Bioengineering, 98(4), pp.764-771.

Liu, Y.-P. et al., 2013. Efficient production of dihydroxyacetone from biodiesel-derived crude glycerol by newly isolated Gluconobacter frateurii. Bioresource Technology, 142, pp.384-389.

Miller, G.L., 1959. Use of dinitrosalicylic acid reagent for determination of reducing sugar. Analytical chemistry, 31(3), pp.426-428.

Leite, G. B.; Paranjabe, K.; Abdelaziz, A. E. M; Hallenbeck, P. C. (2014) Utilization of biodieselderived glycerol or xylose for increased growth and lipid production by indigenous microalgae. Bioresource Technology, in press. Available online 30 October 2014 
Final Version available online at: http://dx.doi.org/10.1016/j.biortech.2014.10.117

Morgunov, I.G., Kamzolova, S.V. \& Lunina, J.N., 2013. The citric acid production from raw glycerol by Yarrowia lipolytica yeast and its regulation. Applied Microbiology and Biotechnology, 97(16), pp.7387-7397.

Nashawi, I.S., Malallah, A. \& Al-Bisharah, M., 2010. Forecasting World Crude Oil Production Using Multicyclic Hubbert Model. Energy \& Fuels, 24(3), pp.17881800.

Pérez, J. et al., 2002. Biodegradation and biological treatments of cellulose, hemicellulose and lignin: an overview. International Microbiology, 5(2), pp.5363.

Rai, M.P., Nigam, S. \& Sharma, R., 2013. Response of growth and fatty acid compositions of Chlorella pyrenoidosa under mixotrophic cultivation with acetate and glycerol for bioenergy application. Biomass and Bioenergy, 58, pp.251-257.

Sabourin-Provost, G. \& Hallenbeck, P.C., 2009. High yield conversion of a crude glycerol fraction from biodiesel production to hydrogen by photofermentation. Bioresource Technology, 100(14), pp.3513-3517.

Shin, H.Y. et al., 2011. Production of Cephalosporin C Using Crude Glycerol in FedBatch Culture of Acremonium chrysogenum M35. Journal of microbiology (Seoul, Korea), 49(5), pp.753-758.

Ukeles, R. \& Rose, W.E., 1976. Observations on organic carbon utilization by photosynthetic marine microalgae. Marine biology, 37(1), pp.11-28.

Xing, R. et al., 2010. Production of jet and diesel fuel range alkanes from waste hemicellulose-derived aqueous solutions. Green Chemistry, 12(11), p.1933.

Xing, R., Qi, W. \& Huber, G.W., 2011. Production of furfural and carboxylic acids from waste aqueous hemicellulose solutions from the pulp and paper and cellulosic ethanol industries. Energy \& Environmental Science, 4(6), p.2193.

Leite, G. B.; Paranjabe, K.; Abdelaziz, A. E. M; Hallenbeck, P. C. (2014) Utilization of biodieselderived glycerol or xylose for increased growth and lipid production by indigenous microalgae. Bioresource Technology, in press. Available online 30 October 2014 
Final Version available online at: http://dx.doi.org/10.1016/j.biortech.2014.10.117

Zeng, X. et al., 2013. Use of biodiesel-derived crude glycerol for vancomycin production by Amycolatopsis orientalis XMU-VS01. Engineering in Life Sciences, 13(1), pp.109-116.

Leite, G. B.; Paranjabe, K.; Abdelaziz, A. E. M; Hallenbeck, P. C. (2014) Utilization of biodieselderived glycerol or xylose for increased growth and lipid production by indigenous microalgae. Bioresource Technology, in press. Available online 30 October 2014 
Final Version available online at: http://dx.doi.org/10.1016/j.biortech.2014.10.117

\section{Tables}

Table 1: Growth rates

\begin{tabular}{cccccc}
\multicolumn{5}{c}{ Growth rate per day $(\mu /$ day $)$} \\
Strain & Ph.Aut & Gly / L & Gly / D & Xyl / L & Xyl / D \\
LB1H09 & 0.83 & 1.32 & 1.24 & 0.57 & 0.79 \\
LB1H10 & 0.65 & 0.95 & 1.11 & 1.10 & 0.85 \\
LB1H12 & 0.88 & 0.77 & 0.52 & 0.45 & 0.51 \\
MA2H01 & 0.94 & 1.28 & 1.25 & 0.74 & 0.65 \\
PCH03 & 0.66 & 1.52 & 1.42 & 0.56 & 0.88 \\
PCH05 & 0.90 & 0.90 & 0.33 & 0.68 & 0.65 \\
PCH06 & 0.98 & 1.29 & 0.59 & 0.73 & 0.64 \\
PCH36 & 0.84 & 1.16 & 0.42 & 0.60 & 0.79 \\
PCH44 & 0.44 & 1.22 & 1.15 & 0.52 & 0.48 \\
PCH90 & 0.95 & 0.81 & 0.38 & 0.74 & 0.63
\end{tabular}

Photoautotrophic growth (Ph.Aut) and mixotrophic growth on glycerol (Gly/L) or xylose $(\mathrm{Xyl} / \mathrm{L})$ or heterotrophic growth $(\mathrm{Gly} / \mathrm{D}$ or $\mathrm{Xyl} / \mathrm{D})$. Refer to Material and Methods (section 2.1) for more details.

Leite, G. B.; Paranjabe, K.; Abdelaziz, A. E. M; Hallenbeck, P. C. (2014) Utilization of biodieselderived glycerol or xylose for increased growth and lipid production by indigenous microalgae. Bioresource Technology, in press. Available online 30 October 2014 
Final Version available online at: $\quad$ http://dx.doi.org/10.1016/j.biortech.2014.10.117

\section{Table S1: Biomass and Lipid Production}

\begin{tabular}{|c|c|c|c|c|c|c|c|c|c|c|}
\hline & \multicolumn{5}{|c|}{ Biomass Production mg/L } & \multicolumn{5}{c|}{ Lipid production mg/L } \\
\hline Strain & Ph.Aut & Gly / L & Gly / D & Xyl / L & Xyl / D & Ph.Aut & Gly / L & Gly / D & Xyl / L & Xyl / D \\
\hline LB1H09 & 1170 & 390 & 430 & 38 & 110 & 42 & 64 & 8 & 4 & 6 \\
\hline LB1H10 & 580 & 900 & 462 & 438 & 314 & 8 & 40 & 12 & 24 & 36 \\
\hline LB1H12 & 11400 & 570 & 456 & 298 & 418 & 14 & 46 & 8 & 22 & 20 \\
\hline MA2H01 & 950 & 450 & 334 & 214 & 422 & 62 & 52 & 10 & 10 & 8 \\
\hline PCH03 & 1020 & 436 & 348 & 44 & 136 & 20 & 40 & 8 & 2 & 4 \\
\hline PCH05 & 1100 & 732 & 240 & 232 & 320 & 26 & 54 & 8 & 16 & 10 \\
\hline PCH06 & 1200 & 874 & 344 & 212 & 404 & 30 & 38 & 8 & 32 & 24 \\
\hline PCH36 & 1100 & 596 & 256 & 212 & 456 & 44 & 46 & 12 & 14 & 10 \\
\hline PCH44 & 500 & 426 & 432 & 50 & 54 & 18 & 40 & 14 & 10 & 4 \\
\hline PCH90 & 960 & 812 & 612 & 340 & 472 & 130 & 108 & 8 & 70 & 22 \\
\hline
\end{tabular}

Photoautotrophic growth (Ph.Aut) and mixotrophic growth on glycerol (Gly/L) or xylose $(\mathrm{Xyl} / \mathrm{L})$ or heterotrophic growth $(\mathrm{Gly} / \mathrm{D}$ or Xyl/D)

Leite, G. B.; Paranjabe, K.; Abdelaziz, A. E. M; Hallenbeck, P. C. (2014) Utilization of biodieselderived glycerol or xylose for increased growth and lipid production by indigenous microalgae. Bioresource Technology, in press. Available online 30 October 2014 
Final Version available online at: http://dx.doi.org/10.1016/j.biortech.2014.10.117

\section{Figure}

Figure 1: Biomass accumulation

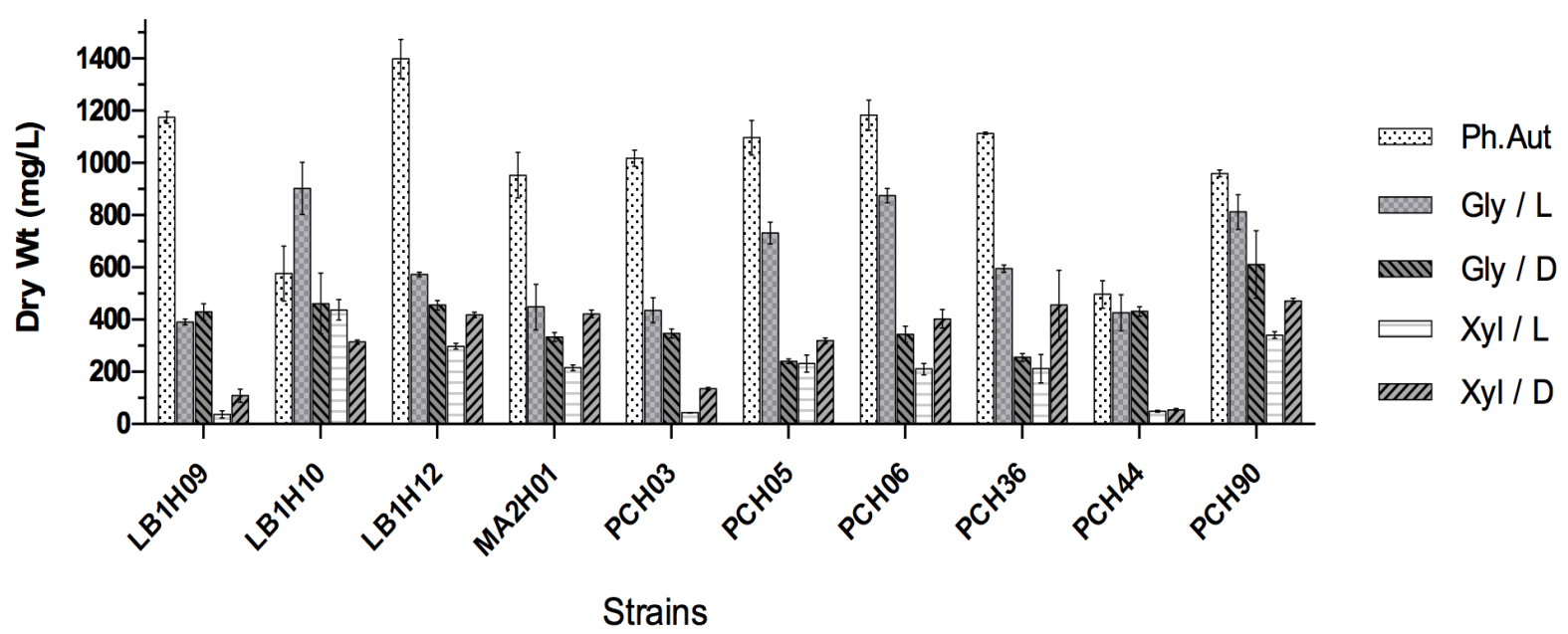

Photoautotrophic growth (Ph.Aut) and mixotrophic growth on glycerol (Gly/L) or xylose $(\mathrm{Xyl} / \mathrm{L})$ or heterotrophic growth $(\mathrm{Gly} / \mathrm{D}$ or $\mathrm{Xyl} / \mathrm{D})$.

Leite, G. B.; Paranjabe, K.; Abdelaziz, A. E. M; Hallenbeck, P. C. (2014) Utilization of biodieselderived glycerol or xylose for increased growth and lipid production by indigenous microalgae. Bioresource Technology, in press. Available online 30 October 2014 
Final Version available online at: $\quad$ http://dx.doi.org/10.1016/j.biortech.2014.10.117

Figure 2: Growth curves patterns
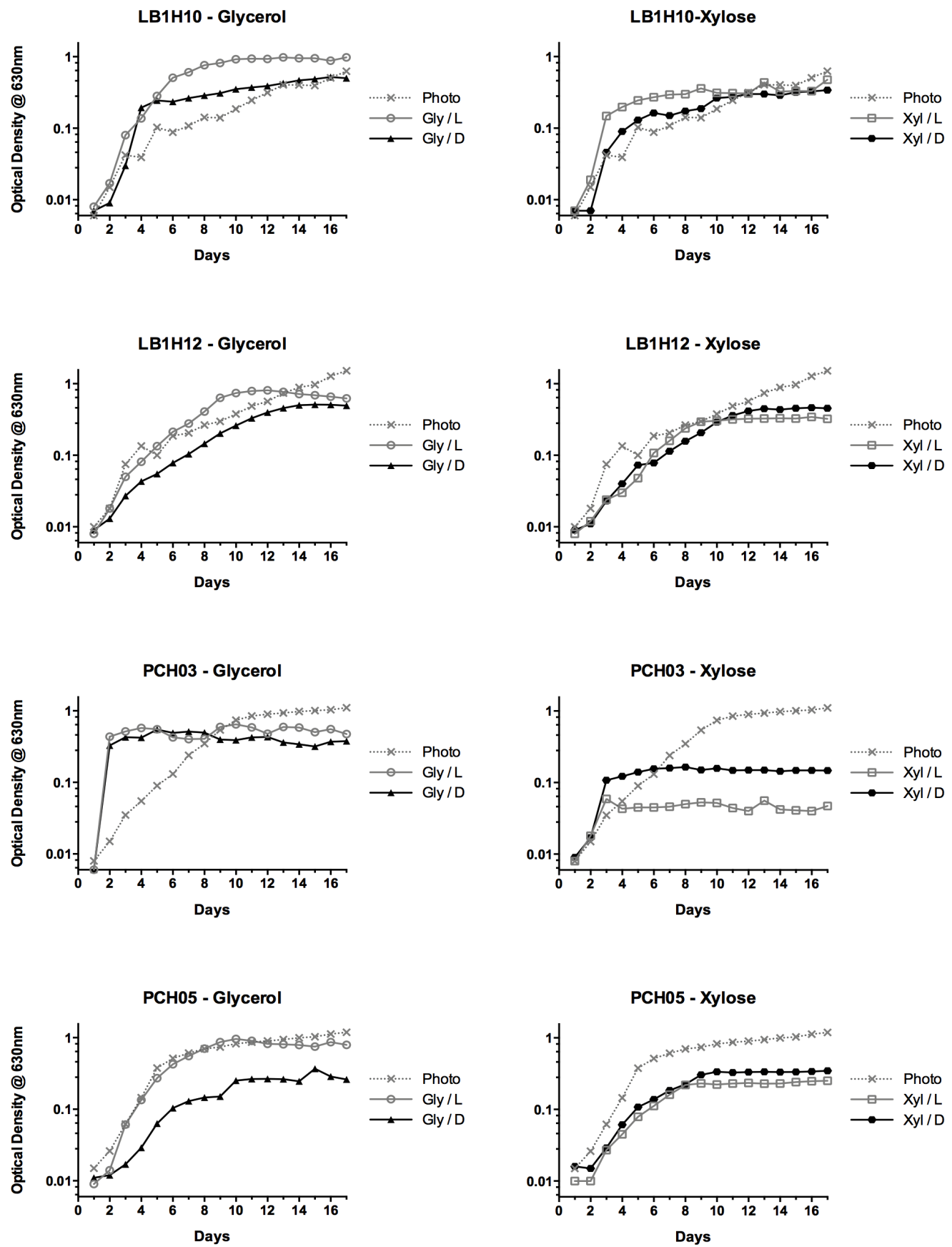

Photoautotrophic growth (Photo) and mixotrophic growth on glycerol (Gly/L) or xylose $(\mathrm{Xyl} / \mathrm{L})$ or heterotrophic growth $(\mathrm{Gly} / \mathrm{D}$ or $\mathrm{Xyl} / \mathrm{D})$. These are representative cases of the patterns found through out this work. Standard deviation (in average 9\%) was omitted to improve clarity of the figure.

Leite, G. B.; Paranjabe, K.; Abdelaziz, A. E. M; Hallenbeck, P. C. (2014) Utilization of biodieselderived glycerol or xylose for increased growth and lipid production by indigenous microalgae.

Bioresource Technology, in press. Available online 30 October 2014 
Final Version available online at: $\quad$ http://dx.doi.org/10.1016/j.biortech.2014.10.117

Figure 3: Comparison of the lipid production performances.

\section{Effects of added fixed carbon on lipid production}

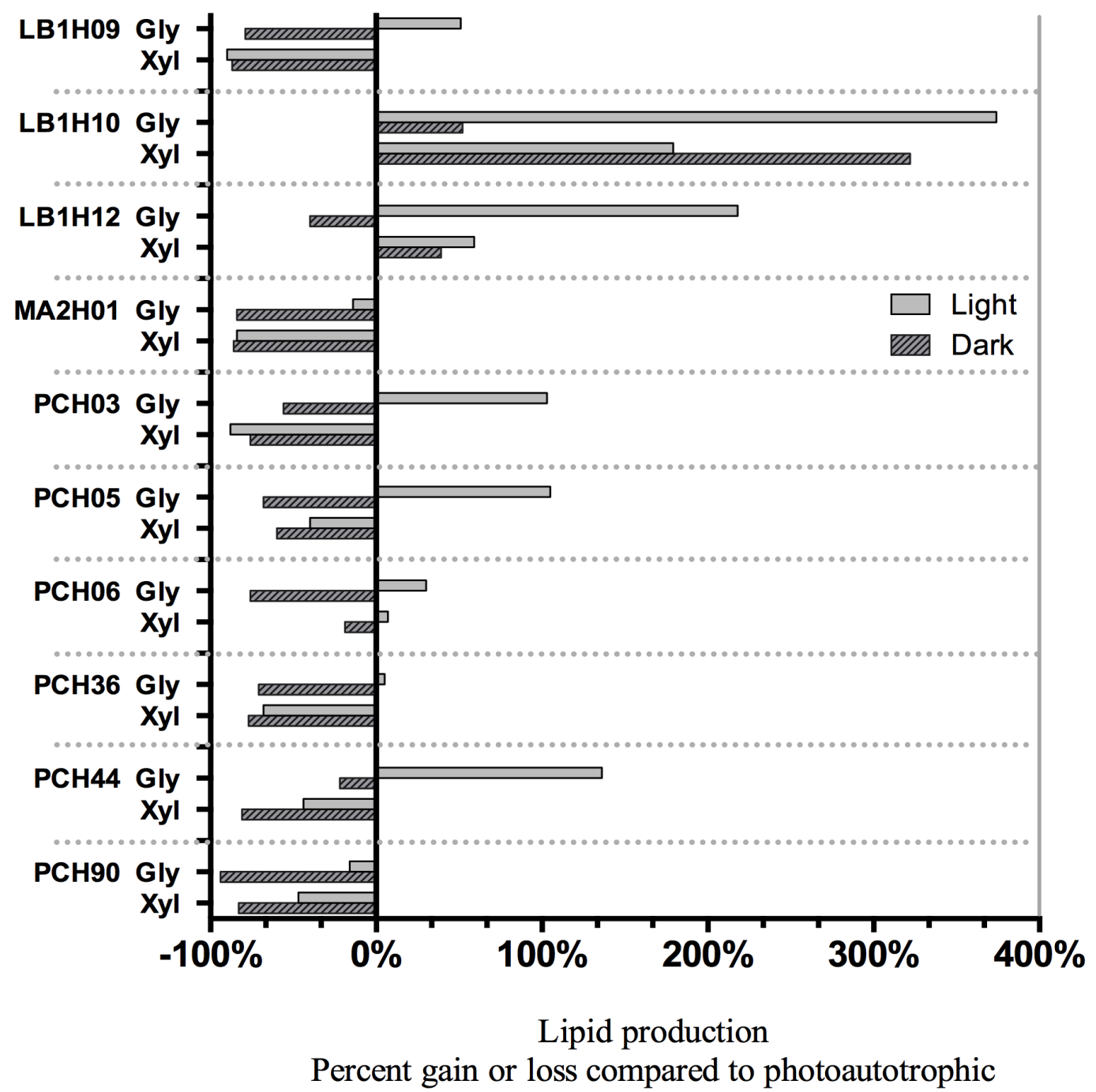

Values are represented as percentage of gain or loss of the mixotrophic (Light) or heterotrophic (Dark) cultivation against the photoautotrophic results. 
Final Version available online at: http://dx.doi.org/10.1016/j.biortech.2014.10.117

\section{Figure 4: Lipid Content}

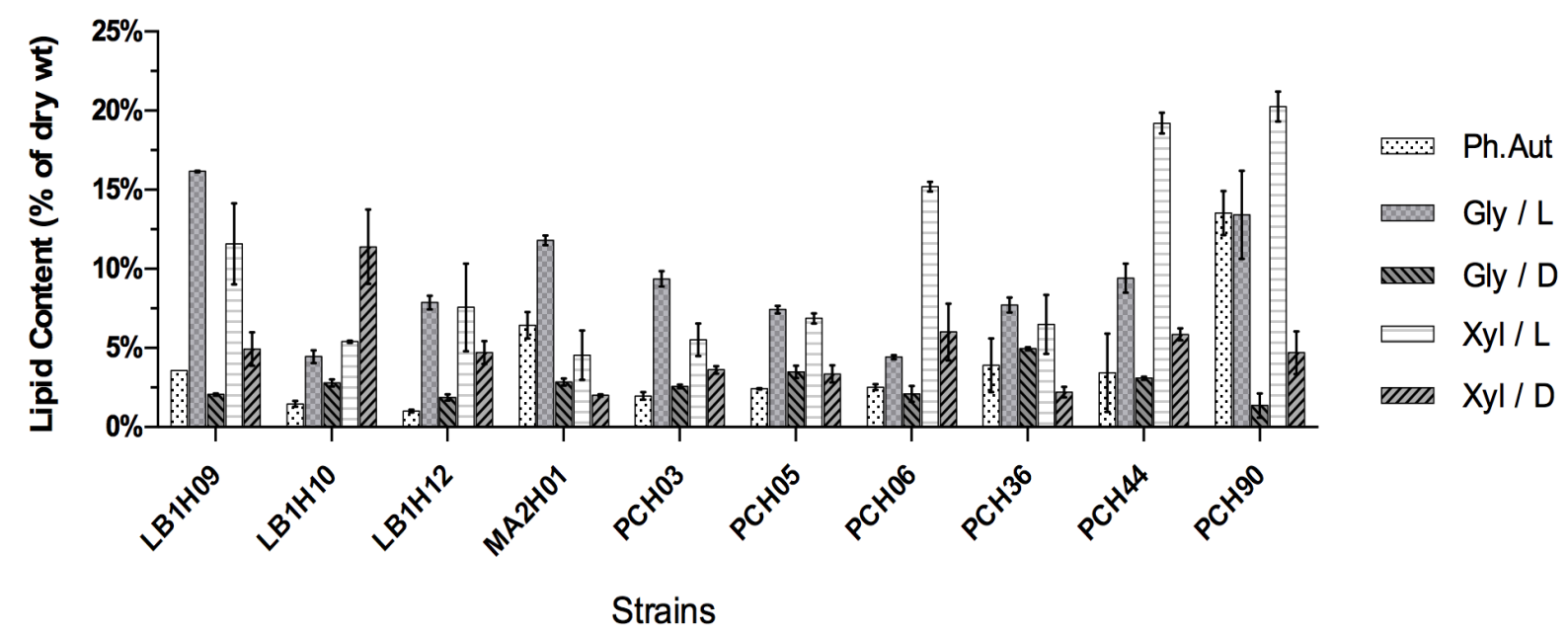

Photoautotrophic growth (Ph.Aut) and mixotrophic growth on glycerol (Gly/L) or xylose $(\mathrm{Xyl} / \mathrm{L})$ or heterotrophic growth $(\mathrm{Gly} / \mathrm{D}$ or $\mathrm{Xyl} / \mathrm{D})$. 
Final Version available online at: $\quad$ http://dx.doi.org/10.1016/j.biortech.2014.10.117

Figure 5: FAME profile of LB1H10 under the different growth conditions.
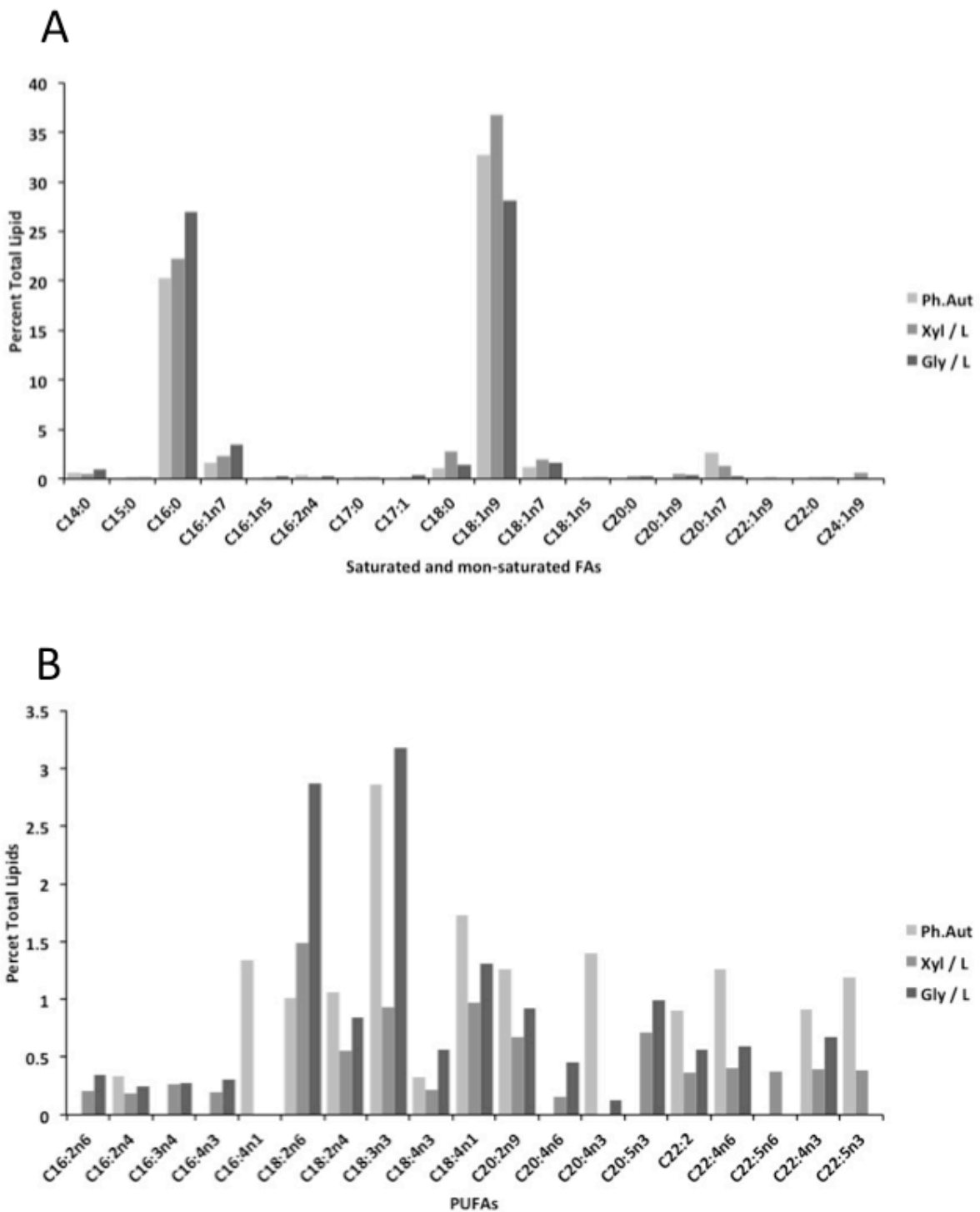

A. Saturated and mono-saturated FAMES are shown as a percentage of total material detected.

B. PUFAs (poly-unsaturated fatty acids) are shown as a percentage of total material detected.

Leite, G. B.; Paranjabe, K.; Abdelaziz, A. E. M; Hallenbeck, P. C. (2014) Utilization of biodieselderived glycerol or xylose for increased growth and lipid production by indigenous microalgae. Bioresource Technology, in press. Available online 30 October 2014 
Final Version available online at: http://dx.doi.org/10.1016/j.biortech.2014.10.117

Leite, G. B.; Paranjabe, K.; Abdelaziz, A. E. M; Hallenbeck, P. C. (2014) Utilization of biodieselderived glycerol or xylose for increased growth and lipid production by indigenous microalgae. Bioresource Technology, in press. Available online 30 October 2014 